\title{
Unprecedented disruption of lives due to COVID-19 pandemic on health of pregnant women
}

\author{
Shashwatee Ghosh, Rujuta Fuke, Disha R. Harikanth*
}

Department of Obstetrics and Gynaecology, Government Medical College and Hospital, Nagpur, Maharashtra, India

Received: 23 September 2021

Accepted: 13 October 2021

\author{
*Correspondence: \\ Dr. Disha R. Harikanth, \\ E-mail: dishaharikanth@gmail.com
}

Copyright: () the author(s), publisher and licensee Medip Academy. This is an open-access article distributed under the terms of the Creative Commons Attribution Non-Commercial License, which permits unrestricted non-commercial use, distribution, and reproduction in any medium, provided the original work is properly cited.

\section{ABSTRACT}

Background: COVID-19 pandemic has caused havoc worldwide. The quarantine imposed in this country aimed at combating this deadly disease and also created awareness amongst the masses. Though there was a decrease in case load; unemployment and food scarcity crumbled the Indian economy. This caused a significant impact on the population especially among the pregnant women. Aim was to assess the effects of measures to control COVID-19 pandemic on the health of pregnant women.

Methods: A cross sectional analytical study conducted in May 2020 among 343 pregnant women attending antenatal outpatient department (OPD) in Government Medical College, Nagpur. They were interviewed using a structured questionnaire.

Results: The study showed that majority women were 25-29 years old and most of them had education of high school level with income under 10,000. Anger and fear were the most common untoward feelings perceived by these pregnant women during pandemic. Most of them had neutral opinion regarding the impact of lockdown on their routine lives. And almost all felt that India would fight the COVID-19 pandemic through lockdown. Majority women reduced their hospital visits during pandemic even-though there was no difficulty in transportation. Although maximum women found it easy to avail medicines in pharmacy there was tremendous food scarcity and decreased earning.

Conclusions: The study stresses on the need to provide mental health awareness among pregnant women during pandemic and to tackle any social inequalities. It also encourages the government to undertake time bound policy evaluation.

Keywords: COVID-19, Pandemic, Quarantine, Pregnant women, Food scarcity, Mental health

\section{INTRODUCTION}

COVID-19 pandemic has caused havoc worldwide. The virus responsible for COVID-19, severe acute respiratory syndrome corona virus-2 (SARS-CoV-2) is in the species of SARS like coronavirus. At $125 \mathrm{~nm}$, it is slightly larger than influenza, SARS and Middle East respiratory syndrome (MERS) viruses. It is a descendent from a bat coronavirus. The closest genome is a virus that originated from the Rhinolophus bat which is $96 \%$ homologous with the SARS- CoV-2 virus. ${ }^{1}$ Amidst this alarming situation,
Indian Prime Minister honourable Narendra Modi asked for janta curfew to be announced on 22 March 2020 from 7 am to 9 pm. It aimed at creating awareness amongst the masses and acknowledging the work of healthcare professionals combating COVID-19 pandemic. On 24 March 2020 the Prime Minister announced nationwide lockdown to contain the pandemic and restrict its further spread. It was noted that there is a significant decrease in growth rate and increase in doubling time of the case because of lockdown. ${ }^{2}$ However there is increase in the unemployment rates crumbling the Indian economy. In 
spite of repeated government assurances, food scarcity amongst daily wagers is also on the rise. Due to this, there has been a considerable increase in the fear, worry and concern among the population at large and particularly amongst certain groups like pregnant women, older age groups and people with underlying health conditions.

In terms of public mental health, the main psychological impact is elevated rates of stress or anxiety. Due to introduction of new measures like quarantine there is increase in loneliness, depression, self-harm and suicidal tendency amongst public. ${ }^{3}$ Pregnancy is a vulnerable state and needs regular antenatal check-up and care. Labor and delivery being emergency situations, also need special attention and no doubt pregnant women are the ones majorly affected by the pandemic. ${ }^{4}$

In this crisis situation of COVID-19 induced lockdown, healthcare professionals face dilemma due to very little information available regarding the psychosocial impact on the health of pregnant women and their challenges to avail healthcare. ${ }^{5,6}$

\section{Aim}

This study aims at assessing the health of pregnant women amidst COVID-19 quarantine and their attitude towards COVID-19 pandemic. This study will further assist the government agencies and health professionals by providing them beneficial information which can be used to safeguard the health and wellbeing of pregnant women at community level in India.

Aim of the study was to assess the effects of measures to control COVID-19 pandemic on the health of pregnant women.

\section{Objectives}

Objectives of the study were: to assess the effect of COVID-19 pandemic on availability of healthcare facilities like emergency medical services, availability of drugs and transportation on the health of pregnant women; to assess the effect of various sociodemographic factors affecting the health of pregnant women during COVID-19 pandemic; and to assess attitude of pregnant women towards COVID-19 pandemic.

\section{METHODS}

This is a cross sectional analytical study conducted in the month of May 2020 (1 month) among 343 pregnant women attending antenatal outpatient department (OPD) in a tertiary health care centre. Ethical committee permission was obtained.

\section{Inclusion criteria}

All pregnant women attending antenatal OPD and willing to participate in the study were included in the study.

\section{Exclusion criteria}

Patients in active labor, diagnosed COVID-19 patients, patients with known psychiatric disorder, patients who are unable or unwilling to provide proper information, and patients with physical or mental handicap who are unable to comprehend and answer the questions were not included in the study.

The participants were pregnant women not infected by the virus epidemiologically. The data was collected by selfprepared structured questionnaire which was prepared first in English and then was translated into Hindi and Marathi. The participant was explained the procedure first and if willing, her consent was taken. The questionnaire was prepared by the investigators based on the variables and objectives of the study. It had two parts, the first half (Q1 to Q11) consisting of demographic and socioeconomic impact of COVID-19 pandemic on heath of pregnant women while the second half (Q12 to 23) denoted the psychological impact of COVID-19 pandemic on health of pregnant women. Demographics included age, educational status, address, occupation, religion and socioeconomic status.

After data collection the response was coded and entered into the computer using Microsoft excel sheets, charts were prepared and the data was analysed using statistical package for the social sciences (SPSS) 21. Descriptive statistical analysis was carried out in the present study.

\section{Literature survey}

Zhang et al have assessed the health and wellbeing of normal adults living and working after one month of confinement to contain the COVID-19 outbreak in China. On 20 February 2020 to 21 February 2020 they surveyed 369 adults in 64 cities in China that varied in their rates of confirmed coronavirus cases on their health conditions, distress and life satisfaction. $27 \%$ of the participants worked at the office, $38 \%$ resorted to working from home and $25 \%$ stopped working due to the outbreak. Those who stopped working reported worse mental and physical conditions as well as distress. The severity of COVID-19 in an individual's home city predicts their life satisfaction and this relationship is contingent upon individual's existing chronic health issues and their hours of exercise. Their evidence supports the need to pay attention to the health of people not infected by the virus, especially for people who stopped working during the outbreak. Their results highlight that physically active people might be more susceptible to wellbeing issues during the lockdown. Policymakers who are considering introducing restrictive measures to contain COVID-19 may benefit from understanding such health and wellbeing implications. ${ }^{1}$

Wu et al assessed the impact of COVID-19 outbreak on the prevalence of depressive and anxiety symptoms and corresponding risk factors among pregnant women across China. They found that pregnant women assessed after 
COVID-19 pandemic had significantly higher rates of depressive symptoms (26\% versus $29.6 \% \mathrm{p}=0.02$ ) than women assess pre epidemic announcement. These women were also more likely to endorse thoughts of self-harm $(p=0.005)$. The depressive rates were positively associated with the number of newly confirmed COVID-19 cases $(p=0.003)$, suspected infections $(p=0.004)$ and death cases per day $(p=0.001)$. Pregnant women who were underweight pre pregnancy, primiparous, <35 years old, employed full time, middle income and had appropriate living space were at increased risk to develop depressive and anxiety symptoms during the outbreak. Strategies targeting maternal stress and isolation such as effective risk communication and the provision of psychological first aid may be particularly useful to prevent negative outcomes for women and their foetuses. ${ }^{4}$

\section{RESULTS}

A total of 343 patients were included in this study.

\section{Socio-demography}

This study observed that $44 \%$ of the women belonged to age group of 25-29 years and more than half (68\%) of the women's husbands were employed as semi-skilled personnel. About $32 \%$ of the women were educated upto high school and $58.6 \%$ of women had income per month ranging from Rs 5001-10000 (Tables 1-4).

Table 1: Age.

\begin{tabular}{|lll|}
\hline Age group (years) & Frequency & Percentage \\
\hline $\mathbf{1 5 - 1 9}$ & 8 & 2.33 \\
\hline $\mathbf{2 0 - 2 4}$ & 125 & 36.44 \\
\hline $\mathbf{2 5 - 2 9}$ & 151 & 44.02 \\
\hline $\mathbf{3 0 - 3 4}$ & 51 & 14.87 \\
\hline $\mathbf{3 5 - 3 9}$ & 8 & 2.33 \\
\hline Total & 343 & 100 \\
\hline
\end{tabular}

\section{Availability of necessities and domestic problems during lockdown}

This study showed that $75.8 \%$ of women experienced no difficulty in transportation to access healthcare during pandemic but still there was reduction in hospital visits during pandemic in $70.5 \%$ of women. Majority $(92.13 \%)$ women had no difficulty in availability of medicines in pharmacy. But $82.5 \%$ women reported food scarcity at home during lockdown. About $70.5 \%$ women had no earning at home during lockdown.

This study also reported that $98.2 \%$ women had no abuse at home during lockdown. Of the $6(1.75 \%)$ women who reported abuse 4 were by their husbands while only 2 by in-laws. All of them were physical. None of the women who experienced abuse neither spoke about it to anyone nor took any treatment for it (Table 5).
Table 2: Husband's occupation according to modified Kuppuswamy classification.

\begin{tabular}{|lll|}
\hline Husband's occupation & Frequency & Percentage \\
\hline Farmer & 14 & 4.08 \\
\hline Profession & 10 & 2.9 \\
\hline Shopkeeper & 32 & 9.3 \\
\hline Skilled & 46 & 13.41 \\
\hline Semi profession & 6 & 1.75 \\
\hline Semi-skilled & 234 & 68.2 \\
\hline Unemployed & 1 & 0.29 \\
\hline Total & 343 & 100 \\
\hline
\end{tabular}

Table 3: Education according to modified Kuppuswamy classification.

\begin{tabular}{|lll|}
\hline Education of women & Frequency & Percentage \\
\hline Post graduate & 22 & 6.42 \\
\hline Graduate & 82 & 23.29 \\
\hline High school & 110 & 32.07 \\
\hline Middle school & 108 & 31.49 \\
\hline Primary school & 17 & 4.96 \\
\hline Illiterate & 4 & 1.16 \\
\hline Total & 343 & 100 \\
\hline
\end{tabular}

Table 4: Income per month according to modified Kuppuswamy classification.

\begin{tabular}{|lll|}
\hline $\begin{array}{l}\text { Income per month } \\
\text { range (Rs) }\end{array}$ & Frequency & Percentage \\
\hline$<\mathbf{5 0 0 0}$ & 35 & 10.2 \\
\hline $\mathbf{5 0 0 1 - 1 0 , 0 0 0}$ & 201 & 58.6 \\
\hline $\mathbf{1 0 , 0 0 1 - 2 0 , 0 0 0}$ & 95 & 27.7 \\
\hline $\mathbf{2 0 , 0 0 0}$ & 12 & 3.5 \\
\hline Total & 343 & 100 \\
\hline
\end{tabular}

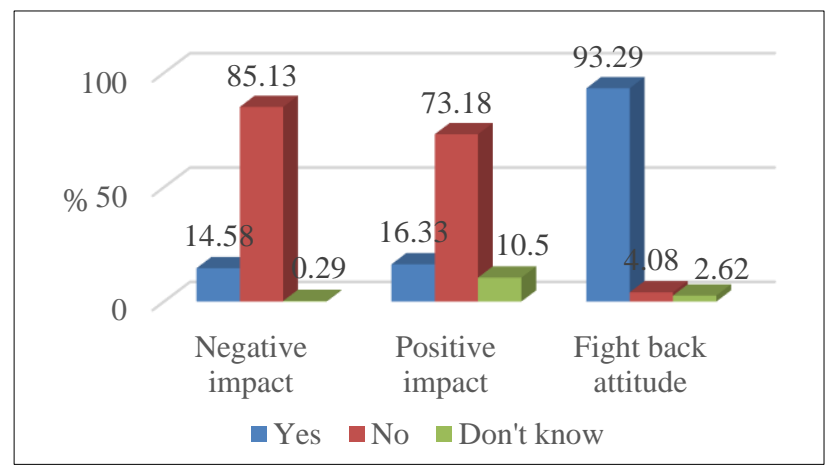

Figure 1: Perceived impact and attitude of women towards lockdown.

\section{Untoward feelings perceived by women during pandemic}

Most women (36\%) reported feeling angry during pandemic followed by fear (33\%). While 23\% women felt anxious, only $19 \%$ women were depressed and $8 \%$ women reported feeling worthless during pandemic (Table 6). 


\section{Perceived impact and attitude of women towards lockdown}

Majority (85\%) women were of the opinion that lockdown had no negative impact on their routine lives. Similarly
$73 \%$ of women were of the opinion that lockdown had no positive impact on their routine lives.

However almost $93 \%$ of the women felt that India would be able to fight the COVID-19 pandemic through lockdown (Table 7 and Figure 1).

Table 5: Availability of necessities and domestic problems during lockdown.

\begin{tabular}{|c|c|c|c|c|c|c|c|}
\hline \multirow{2}{*}{$\begin{array}{l}\text { S. } \\
\text { no. }\end{array}$} & \multirow{2}{*}{ Questions } & \multicolumn{2}{|l|}{ Yes } & \multicolumn{2}{|l|}{ No } & \multicolumn{2}{|c|}{ Don't know } \\
\hline & & $\mathbf{N}$ & $\%$ & $\mathbf{N}$ & $\%$ & $\mathbf{N}$ & $\%$ \\
\hline 1 & Difficulty in transportation to access healthcare in the pandemic & 83 & 24.2 & 260 & 75.8 & & \\
\hline 2 & Reduction in hospital visits & 242 & 70.55 & 100 & 29.15 & 1 & 0.29 \\
\hline 3 & Availability of medicines in pharmacy & 316 & 92.13 & 27 & 7.87 & & \\
\hline 4 & Food availability at home & 60 & 17.49 & 283 & 82.51 & & \\
\hline 5 & Earning at home & 101 & 29.45 & 242 & 70.55 & & \\
\hline 6 & Abuse at home & 6 & 1.75 & 337 & 98.25 & & \\
\hline
\end{tabular}

Table 6: Untoward feelings perceived by women during pandemic

\begin{tabular}{|llllllll|}
\hline $\begin{array}{l}\text { S. } \\
\text { no. }\end{array}$ & Feelings during & Yes & & No & & \multicolumn{2}{c|}{ Don't know } \\
\hline $\mathbf{1}$ & Fear & Number & $\mathbf{\%}$ & Number & $\mathbf{\%}$ & Number & \% \\
\hline $\mathbf{2}$ & Anxiety & 113 & 32.94 & 229 & 66.76 & 1 & 0.29 \\
\hline $\mathbf{3}$ & Depressed & 80 & 23.32 & 263 & 76.68 & 0 & 0.00 \\
\hline $\mathbf{4}$ & Worthless & 64 & 18.66 & 279 & 81.34 & 0 & 0.00 \\
\hline $\mathbf{5}$ & Angry & 29 & 8.45 & 312 & 90.96 & 2 & 0.58 \\
\hline
\end{tabular}

Table 7: Perceived impact and attitude of women towards lockdown.

\begin{tabular}{|llllllc|}
\hline Aspects during lockdown & Yes & & No & \multicolumn{3}{c|}{ Don't know } \\
\cline { 2 - 8 } & Number & \% & Number & \% & Number & \% \\
\hline Negative impact of lockdown & 50 & 14.58 & 293 & 85.13 & 0 & 0.29 \\
\hline Positive impact of lockdown & 80 & 16.33 & 263 & 73.18 & 36 & 10.5 \\
\hline $\begin{array}{l}\text { Attitude to fight down COVID-19 } \\
\text { pandemic }\end{array}$ & 64 & 93.29 & 14 & 4.08 & 9 & 2.62 \\
\hline
\end{tabular}

\section{DISCUSSION}

COVID-19 pandemic has brought a significant and drastic change in the lives of pregnant women due to movement restrictions in terms of food, security, communication, economy, employment, and domestic routine, access to health care and mental well-being.

Consistent with the study of Chu et al, and Sahin et al our study shows a reduction in hospital visits thereby limiting the access to health care by the pregnant women. ${ }^{7,8}$ Prenatal procedures have changed in some countries like England and Japan due to pandemic. While prenatal care services are postponed except for mandatory situations, pregnant women are asked only to come to birth in some countries. ${ }^{9,10}$ These decisions affect the women's choices and causes fear about their pregnancy and childbirth care. This increases the need for assurance and support by health care professionals during pregnancy, childbirth and post- partum. There may be changes in the health care workers serving the pregnant women in pandemic and limitation in the number of staff due to change in work plan. This raises the need for guidelines for healthcare professionals about provision of proper care without exposing healthy pregnant women to the disease.

Our study shows significant percentage of food scarcity faced by pregnant women in pandemic. Mass quarantineinduced mobility restrictions impacted every step of the food supply chain, including production, transportation, access and storage. In a study conducted in China, Mihashi et al reported that delayed supply caused by limited transportation could aggravate psychological distress (anxiety) among Chinese individuals. ${ }^{11}$ Pellecchia et al revealed that some villages in Liberia disobeyed the enforced quarantine order due to intermittent food supply. ${ }^{12}$ With regards to increased food scarcity majority of the surveyed respondents in studies agreed that 
government should provide quarantined individuals with food, shelter and other basic needs. ${ }^{13,14}$

A decrease in income at home and increase in unemployment has been observed in this study during pandemic. A widespread economic impact at both business and individual levels has been noticed by mass quarantine by limiting personal movement and transportation of goods. Kodish et al indicated that decreased production of grains and reduced mobility of traders interrupted the domestic and international flow of agricultural trade. ${ }^{15}$ Gostin et al reported that travel restrictions caused enormous damage to business relying on mobility and individuals having economic interests in tourism. ${ }^{16}$ None of the studies provided macroeconomic data (e.g. change in gross domestic product per capita) to support their findings. In all the studies majority of the respondents argued that government should compensate individuals for their lost earnings during quarantine.

Our study showed neither any difficulty in transportation to access healthcare nor any scarcity of medicines in pharmacy during pandemic. It also reported that there was no significant increase in domestic violence at home during pandemic. This is in contrast to the study of John et al who maintained that the trend of domestic violence cases escalated since COVID-19 lockdown in both Hubei province, China and United Kingdom. ${ }^{17}$ This under reporting may be due to cultural barriers in India where women are hesitant to reveal about their experiences of domestic violence for the fear of abandonment and social pressure. Domestic violence is seen less in pregnant women than in non-pregnant women. Being pregnant could be a reason. Most of the studies emphasized the invisibility of gendered homecare in countries undergoing mass quarantine and called for rights- based support to prevent violence against women.

In the present study, psychological distress was experienced among pregnant women during pandemic in the form of anger followed by fear, anxiety, depression and worthlessness. Zhang et al reported a strong evidence that those who stopped working had poorer mental health conditions than those still employed. ${ }^{1}$ Sahin et al reported that in the pandemic process, daily routine, social life and leisure activities of pregnant women can change due to social distancing and self-isolation practices. ${ }^{8}$ Their cleaning routine at home increased due to fear of infection. Personal protection measures such as hygiene practices to avoid infection may increase by pregnant women due to high level of stress and anxiety against the risk of virus transmission. These extreme measures may have negative outcome on their mental health. It is known that social support is necessary to increase resilience in times of crisis and poor social support is associated with negative psychological consequences. Literature has shown that support from pregnant woman's partner, mother, other family members and peers in the perinatal period is important in reducing stress, improving coping skills, preventing depression and adapting to new roles as a mother during pregnancy and childbirth.

In our study, though pregnant women felt that COVID-19 pandemic brought many negative things like food scarcity, economic disruption, unemployment, reduction in hospital visits and psychological distress, some women also opined it brought many positive aspects like spending time with loved ones, reduction in pollution, restoration of environment and expression of true human nature in crisis. Most of the women in our study were of the opinion that India would be able to fight COVID-19 pandemic by enforcing lockdown. According to Cava et al, in contrast to negative implications, altruism was identified as a positive consequence. ${ }^{18}$ While promoting altruism, policymakers should develop culturally competent and context-specific interventions, facilitate the use of technology to retain social connections and increase the capacity of health care services with digital innovations.

This study has certain limitations. Firstly it is subject to sampling bias with heterogenous characteristics of research populations (e.g. urban, rural, high income, low income). Hence future research should aim to minimize potential biases and consider interaction among each of social determinants of health in countries with different political systems.

Secondly scarcity of COVID-19 related cases at the time of data collection (May 2020) has limited transferability of our results as the amount of research on COVID-19 related movement restrictions has grown exponentially and data on longer term effects of COVID-19 mass quarantine will not be available until much later.

Thirdly this study involves pregnant women only in one portion of our country. However the experiences of these women may be shared by the women in other portion of our country and other countries and this information may be relevant globally for health care professionals working with pregnant women and their families.

\section{CONCLUSION}

The study shows that coronavirus pandemic has significantly disrupted the day to day routine of pregnant women. Our study emphasizes on scarcity of basic necessities like food, reduced access to healthcare and unemployment during pandemic. This has created a sense of fear and anxiety among the minds of pregnant women .There is a need to provide mental health awareness among pregnant women during pandemic and collaborate with mental health experts if necessary. Also further research is essential to follow up the post-natal experiences of these pregnant women as they have increased risk of postpartum depression. Providing proper communication and support by health care worker and those with similar experiences helps in relieving stress during pregnancy. Also multisectoral actions should be taken by the government to tackle social inequalities, provide clear and coherent 
guidance to the public and undertake time bound policy evaluation. Such efforts will minimize negative consequence of COVID-19 pandemic and establish preparedness for future public health emergencies.

\section{ACKNOWLEDGMENTS}

Authors would like to thank participants to share their perceptions. They would also like to thank the staff of department of obstetrics and gynaecology to extend their support in conducting the study.

Funding: No funding sources Conflict of interest: None declared

Ethical approval: The study was approved by the Institutional Ethics Committee

\section{REFERENCES}

1. Zhang SX, Wang Y, Rauch A, Wei F. Unprecedented disruption of lives and work: Health, distress and life satisfaction of working adults in China one month into the COVID-19 outbreak. Psychiatry Res. 2020;288:112958.

2. San Lau L, Samari G, Moresky RT, Casey SE, Kachur SP, Roberts LF, et al. COVID-19 in humanitarian settings and lessons learned from past epidemics. Nature Med. 2020:26(5):647-8.

3. Fardin MA. COVID-19 and Anxiety: A Review of Psychological Impacts of Infectious Disease Outbreaks. Arch Clin Infect Dis. 2020;15:e102779.

4. Wu Y, Zhang C, Liu H, Duan C, Li C, Fan J, et al. Perinatal depressive and anxiety symptoms of pregnant women during the coronavirus disease 2019 outbreak in China. Am J Obstet Gynecol. 2020;223(2):240.e1-9.

5. Zhou P, Yang XL, Wang XG, Hu B, Zhang L, Zhang $\mathrm{W}$, et al. A pneumonia outbreak associated with a new coronavirus of probable bat origin. Nature. 2020;579(7798):270-3.

6. Patel A, Jernigan DB; 2019-nCoV CDC Response Team. Initial Public Health Response and Interim Clinical Guidance for the 2019 Novel Coronavirus Outbreak - United States, December 31, 2019February 4, 2020. MMWR Morb Mortal Wkly Rep. 2020;69(5):140-6.

7. Chu IY, Alam P, Larson HJ, Lin L. Social consequences of mass quarantine during epidemics: a systematic review with implications for the COVID19 response. J Travel Med. 2020;27(7):192.
8. Mizrak Sahin B, Kabakci EN. The experiences of pregnant women during the COVID-19 pandemic in Turkey: A qualitative study. Women Birth. 2021:34(2):162-9.

9. Walton G. COVID-19 The new normal for midwives, women and families. Midwifery. 2020;87:102736.

10. Furuta M. International Year of Midwifery- in the midst of a pandemic. Midwifery. 2020;87:102739.

11. Mihashi M, Otsubo Y, Yinjuan X, Nagatomi K, Hoshiko $\mathrm{M}$, Ishitake $\mathrm{T}$. Predictive factors of psychological disorder development during recovery following SARS outbreak. Health Psychol. 2009;28(1):91-100.

12. Pellechia U, Crestani R, Decroo T. Social consequences of Ebola containment measures in Liberia. PLoS One. 2015;10:e0143036.

13. Tracy CS, Rea E, Upshur RE. Public perceptions of quarantine: community- based telephone survey following an infectious disease outbreak. BMC Public Health. 2009;9:470.

14. Wilken JA, Pordell P, Goode B, Jarteh R, Miller Z, Saygar BG, et al. Knowledge, Attitudes, and Practices among Members of Households Actively Monitored or Quarantined to Prevent Transmission of Ebola Virus Disease - Margibi County, Liberia: FebruaryMarch 2015. Prehosp Disaster Med. 2017;32(6):6738.

15. Kodish SR, Bio F, Oemcke R. A qualitative study to understand how Ebola virus disease affected nutrition in Sierra Leone-a food value chain framework for improving future response strategies. PLoS Negl Trop Dis. 2019;13:e0007645.

16. Gostin LO, Bayer R, Fairchild AL. Ethical and legal challenges posed by severe acute respiratory syndrome. JAMA. 2003;290:3229-37.

17. John N, Casey S, Carino G, McGovern T. Lessons never learned: crisis and gender -based violence. Dev World Bioeth. 2020;1-4.

18. Cava MA, Fay KE, Beanlands HJ. The experience of quarantine for individuals affected by SARS in Toronto. Public Health Nurs. 2005;22:398-406.

Cite this article as: Ghosh S, Fuke R, Harikanth DR. Unprecedented disruption of lives due to COVID-19 pandemic on health of pregnant women. Int J Reprod Contracept Obstet Gynecol 2021;10:4125-30. 